Journal of Epidemiology and Public Health (2019), 4(4): 296-306

https://doi.org/10.26911/jepublichealth.2019.04.04.04

\title{
Meta-analysis on The Effects of Hypertension, Type II Diabetes Mellitus, and Smoking on the Risk of Stroke among Asian Young Adult Population
}

\author{
Windhy Monica1), Vitri Widyaningsih²), Endang Sutisna Sulaeman²) \\ 1)Masters Program in Public Health, Universitas Sebelas Maret \\ ${ }^{2)}$ Faculty of Medicine, Universitas Sebelas Maret
}

\begin{abstract}
Background: The incidence of stroke at a young age is reported to increase. Stroke at a young age is still often found in classic risk factors that can be changed such as hypertension, dyslipidemia, and type II diabetes mellitus (type II DM). Control of the right risk factors will affect the incidence of stroke. This study aims to analyze stroke risk factors in young populations in Asia.

Subjects and Method: This study is a meta-analysis carried out using PRISMA systematic guidelines. The article is a study conducted between 2000 until 2019. The process of searching articles using a search engine database consisting of PubMed, Clinical Key, and Google Scholar using the keywords "risk factor", "stroke", "adult", "young adult ", And" Asia ". The analysis was done with the Review Manager (RevMan) software 5.3.

Results: The results showed eight articles fulfilled the criteria which contained 26,360 samples. The results showed that hypertensive young adults, type II DM, and smoking had a stroke risk at a young age of 6.6 times (OR 6.66; 95\% CI 6.10 to 7.27), 3.7 times (OR 3.72; 95\% CI 3.17 to 4.38), and 2.6 times (OR 2.64; CI 95\% 1.77 to 3.93) higher, than those without hypertension, type II DM, and smoking, and was statistically significant.

Conclusion: hypertension, type II diabetes, and smoking are risk factors for stroke at a young age.
\end{abstract}

Keywords: young, adult, stroke, risk factor, meta-analysis

Correspondence:

Windhy Monica. Masters Program in Public Health, Universitas Sebelas Maret. Jl. Ir. Sutami 36 A, Surakarta 57126, Central Java. Email: wmonica@gmail.com. Mobile: 082221223355

\section{BACKGROUND}

Stroke accounts for the second highest number of deaths in the world after heart disease (WHO, 2018). Although stroke is a problem in all developed and developing countries, the burden of the disease is very serious in Asia, including in Indonesia. Based on the results of the basic health research survey (2018), compared to 2013 the prevalence of stroke in Indonesia increased from $7 \%$ to $10.9 \%$. This is in line with the prevalence of hypertension which also increased from $25.8 \%$ to $34.1 \%$ (Riskesdas, 2018).
The incidence of stroke at a young age (less than 45 years) is reported to continue to increase (Smajlović, 2015). The average number of years lost due to disability or disability-adjusted life years due to stroke is ranked 3 rd in the world (Feigin, 2017). Compared to strokes in the elderly, strokes that attack young people have a huge economic impact because they cause disability in productive age (Singhal et al., 2013). The incidence of recurrent strokes and cognitive impairment has also been reported to increase in stroke patients in young age (Maaijwee et al., 2014). 
Risk factors for the cause of stroke vary widely. The increase of the age is very influential, but the incidence of stroke at a young age is still often found classic risk factors that can be changed such as hypertension, dyslipidemia, and diabetes mellitus (DM). Control of the right risk factors will affect the incidence of stroke.

Meta-analysis is analysis of the study that combines the results of existing studies and analyzes them and then draws general conclusions from the analysis that has been carried out (Liberati et al., 2009). Metaanalysis is useful for presenting the latest evidence based; one of them is to provide evidence for doctors and policy makers to assess the prognosis of risk factors possessed by a person with the disease (Haidich, 2010). Stroke at a young age can be prevented by early detection and control of known risk factors thoroughly (Sousa \& Ribeiro, 2009). A study on stroke risk factors at a young age in Asia shows mixed results. The purpose of this study was to determine the incidence and analyze risk factors for stroke at a young age in Asia so that a summary of the studies that had been conducted beforehand could be known.

\section{SUBJECTS AND METHOD}

\section{a. Study Design}

This study is a meta-analysis study. It used the secondary data in the form of data from the results of previous studies. The data is sought from a systematic and comprehensive database of several indexes including; PubMed, ClinicalKey, and Google Scholar, use "young" "adult", "risk factor", "stroke" and "Asia" search keywords.

\section{b. Inclusion Criteria}

The inclusion criteria in this study were full paper articles with observational methods. Stroke diagnosis is based on physical examination and radiology using CT scans and / or MRI.

\section{c. Study Variables}

Stroke: Stroke is a clinical syndrome that develops rapidly due to focal and global brain disorders with symptoms lasting 24 hours or more. It is said that a stroke is diagnosed if a typical abnormal neurological examination is found accompanied by a radiological examination.

Hypertension: Hypertension is an increase in systolic blood pressure greater than $140 \mathrm{mmHg}$ and / or diastolic greater than $90 \mathrm{mmHg}$ on two measurements with an interval of five minutes in a state of adequate rest (calm).

Diabetes Melitus type II: Type II DM is an increase in blood sugar (more than 200 $\mathrm{mg} / \mathrm{dL}$ ) due to insulin resistance accompanied by a relative deficiency of insulin secretion.

Smoking: Smoking is the activity of sucking smoke from tobacco using pipes or cigarettes as measured by the intensity of smoking.

\section{d. Exclusion Criteria}

The exclusion criteria are patients who experience strokes more than once and / or with complications.

\section{e. Study Instruments}

The instrument used to collect the data was published articles between 2000 and 2019 whose study was conducted on the Asian continent contained in PubMed, ClinicalKey, and Google Scholar databases.

\section{f. Data Analysis}

Data analysis was carried out using Review Manager (Rev-Man) software 5.3 released by the Cochrane Collaboration. RevMan was used to calculate the adjusted Odds Ratio (aOR) as a whole

\section{RESULTS}

The data was sought from a systematic and comprehensive database of several indexes including; PubMed, Clinical Key, and Google Scholar. The results of article 
search, there were 653 selected articles can be seen in Figure 1.

After a review of full text articles, articles were found that did not contain the

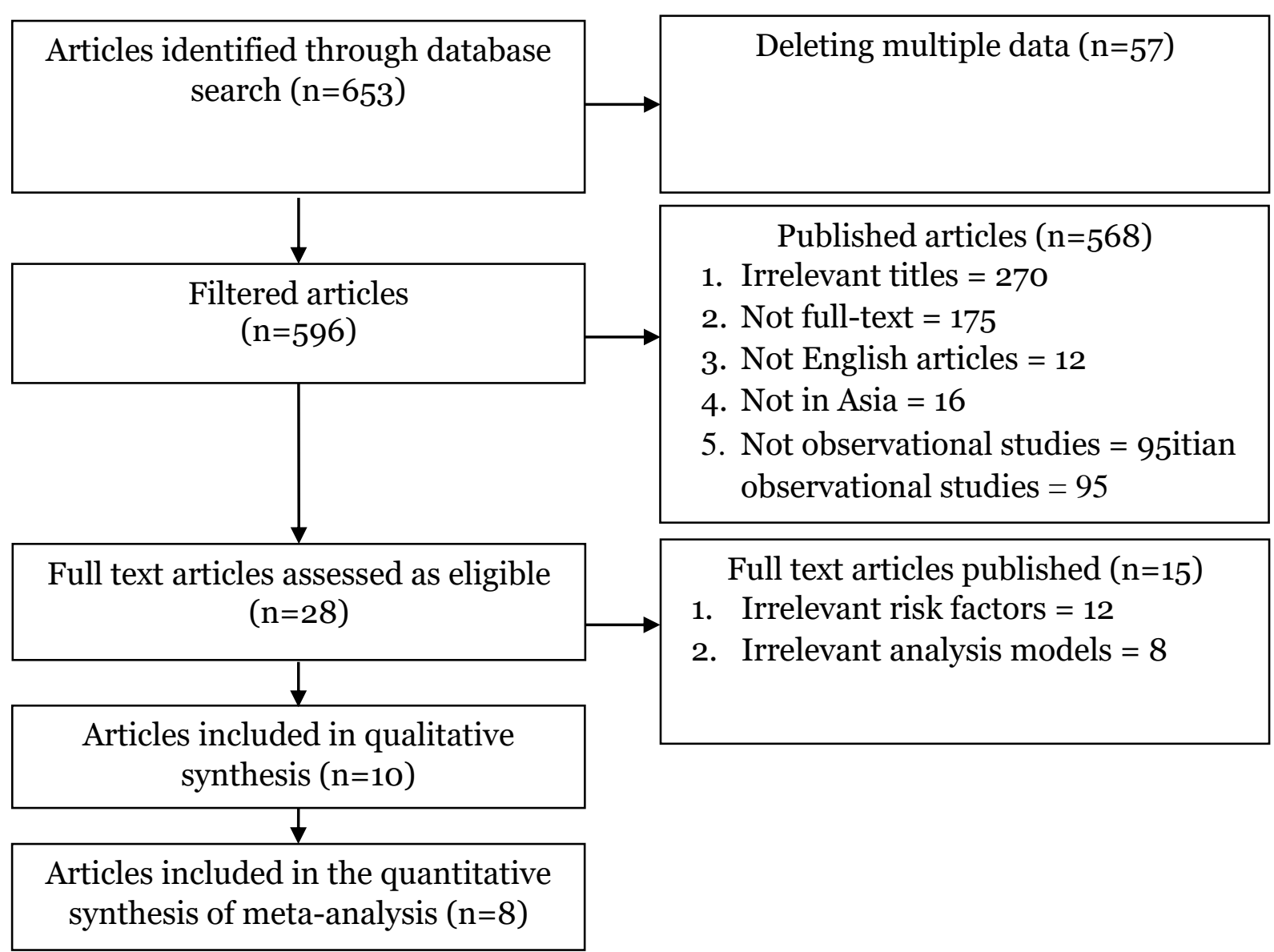

risk factors studied (hypertension, type II diabetes mellitus, and smoking). 
points on the right and left side compared to the standard error (Murti, 2018).

Based on the articles identified from the review results, 8 articles were qualified as sources for meta-analysis. Then the articles that have been obtained will be analyzed using RevMen 5.3 and the results will be presented in the form of a forest plot and funnel plot.

\section{Hypertension}

There were six articles that meet the requirements identified from the results of the review. A summary of each study is shown in Table 1.

Figure 2 shows that 6 articles reported that hypertension is a risk factor for stroke at a young age. The results obtained showed a high heterogeneity between trials ( $\mathrm{p}>0.001$; I2 = 74\%) so that the random effects model was used. Hypertension can increase 6.6 times the risk of having a stroke at a young age (OR 6.66; $95 \%$ CI 6.10 to 7.27). Figure 5 shows a symmetrical face facing down indicating no publication bias in the study.

\section{Diabetes Melitus type II}

There were five articles that meet the requirements identified from the results of the review. A summary of each study is shown in Table 2.

Figure 3 shows five articles reporting that type II DM is a risk factor for stroke at a young age. The results obtained indicate high heterogeneity between trials ( $p>$ 0.001; I2 $=75 \%$ ) so that the random effects model is used. Type II DM can increase 3.7 times the risk of having a stroke at a young age (OR 3.72; 95\% CI 3.17 to 4.38). Figure 6 shows a symmetrical face facing down indicating that there was no publication bias in the study.

\section{Smoking}

There were six articles that meet the requirements identified from the results of the review. A summary of each study is shown in Table 3. 
Journal of Epidemiology and Public Health (2019), 4(4): 296-306

https://doi.org/10.26911/jepublichealth.2019.04.04.04

Table 1. An article summary of the source of the relationship between hypertension and the risk of stroke at a young age

\begin{tabular}{|c|c|c|c|c|c|c|c|c|}
\hline \multirow[t]{2}{*}{ Author } & \multirow[t]{2}{*}{ Year } & \multirow{2}{*}{$\begin{array}{c}\text { Samples } \\
\text { characteristics } \\
\text { Age (year) }\end{array}$} & \multicolumn{4}{|c|}{ Characteristics } & \multicolumn{2}{|c|}{ Level of severity } \\
\hline & & & Location & Design & $\begin{array}{l}\text { Sample } \\
\text { size }\end{array}$ & Innclusion Criteria & $\mathrm{aOR}$ & $\mathrm{CI}$ \\
\hline Bi et al. & 2002 & $35-45$ & China & Case control & 14,248 & First onset, without complications & 6.64 & $5.96-7.40$ \\
\hline Chiu et al. & 2015 & $18-45$ & Taiwan & Case-control & 10,315 & First onset, without complications & $7 \cdot 32$ & $6.25-8.57$ \\
\hline Fan et al. & 2018 & $18-49$ & China & Cohort & 400 & First onset, without complications & 39.9 & $3.99-400.98$ \\
\hline Khan & 2007 & $17-45$ & Qatar & Cohort & 40 & First onset, without complications & 1.34 & $0.29-6.19$ \\
\hline Lipska et al. & 2007 & $15-45$ & India & Case control & 310 & First onset, without complications & 2.46 & $1.25-4.84$ \\
\hline Niu et al. & 2014 & $15-49$ & China & Case control & 184 & First onset, without complications & 3.50 & $1.63-7.50$ \\
\hline
\end{tabular}

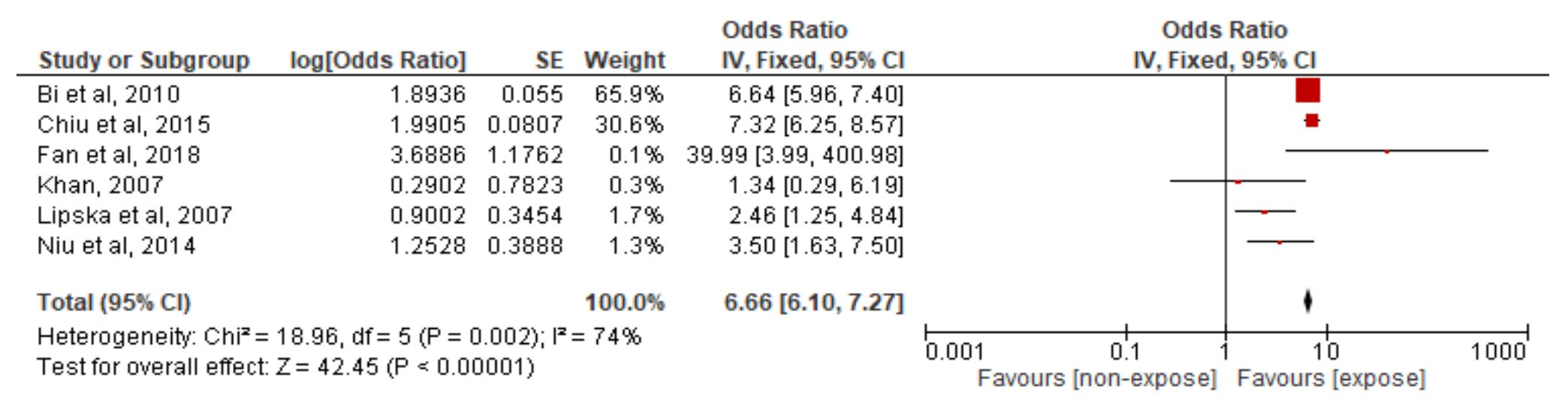

Figure 2. Meta-analysis of hypertension and risk of stroke at a young age 
Table 2. Summary of articles on the source of relationship between type II DM and stroke risk at a young age

\begin{tabular}{|c|c|c|c|c|c|c|c|c|}
\hline \multirow[t]{2}{*}{ Author } & \multirow[t]{2}{*}{ Year } & \multirow{2}{*}{$\begin{array}{c}\text { Samples } \\
\text { Characteristic } \\
\text { s } \\
\text { Age (year) }\end{array}$} & \multicolumn{4}{|c|}{ Characteristics } & \multicolumn{2}{|c|}{ Level of severity } \\
\hline & & & $\begin{array}{l}\text { Locatio } \\
\text { n }\end{array}$ & Design & $\begin{array}{l}\text { Sample } \\
\text { size }\end{array}$ & Inclusion Criteria & $\mathrm{aOR}$ & $\mathrm{CI}$ \\
\hline Bi et al. & 2002 & $35-45$ & China & Case control & 14,248 & First onset, without complications & 3.01 & $2.37-3.82$ \\
\hline Chiu et al. & 2015 & $18-45$ & Taiwan & Case control & 10,315 & First onset, without complications & 5.20 & $4.09-6.62$ \\
\hline Fan et al. & 2018 & $18-49$ & China & Case control & 400 & First onset, without complications & 1.63 & $0.41-6.43$ \\
\hline Lipska et al. & 2007 & $15-45$ & India & Case control & 310 & First onset, without complications & 2.94 & $0.93-9.29$ \\
\hline Niu et al. & 2014 & $15-49$ & China & Case control & 184 & First onset, without complications & 1.70 & $0.80-3.61$ \\
\hline
\end{tabular}

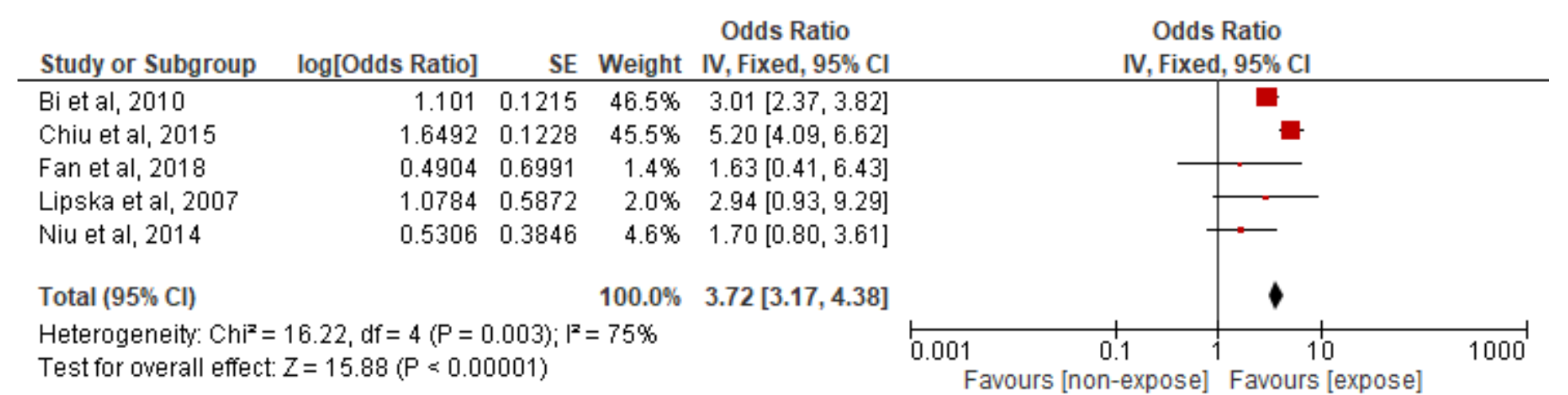

Figure 3. Meta-analysis of type II DM and risk of stroke at a young age 
Journal of Epidemiology and Public Health (2019), 4(4): 296-306

https://doi.org/10.26911/jepublichealth.2019.04.04.04

Table 3. Summary of articles on the relationship between smoking and risk of stroke at a young age

\begin{tabular}{|c|c|c|c|c|c|c|c|c|}
\hline \multirow[t]{2}{*}{ Author } & \multirow[t]{2}{*}{ Year } & \multirow{2}{*}{$\begin{array}{l}\text { Samples } \\
\text { Characteristics } \\
\text { Age (year) }\end{array}$} & \multicolumn{4}{|c|}{ Characteristics } & \multicolumn{2}{|c|}{ Level of severity } \\
\hline & & & Location & Design & $\begin{array}{l}\text { Sample } \\
\text { size }\end{array}$ & Inclusion Criteria & $\mathrm{aOR}$ & $\mathrm{CI}$ \\
\hline Khan & 2007 & $17-45$ & Qatar & Cohort & 40 & First onset, without complications & 1.33 & $0.18-9.46$ \\
\hline Lipska et al. & 2007 & $15-45$ & India & Case control & 310 & First onset, without complications & 7.14 & $2.90-17.54$ \\
\hline Niu et al. & 2014 & $15-49$ & Cina & Case control & 184 & First onset, without complications & 2.6 & $1.2-5.8$ \\
\hline Tiamkao et al. & 2013 & $<45$ & Thailand & Case control & 782 & First onset, without complications & 1.03 & $0.37-2.83$ \\
\hline Fan et al. & 2018 & $18-49$ & Cina & Case control & 400 & First onset, without complications & 1.840 & $0.47-7.09$ \\
\hline Mishra et al. & & $<50$ & India & Case control & 45 & First onset, without complications & 3.00 & $0.97-9.30$ \\
\hline
\end{tabular}

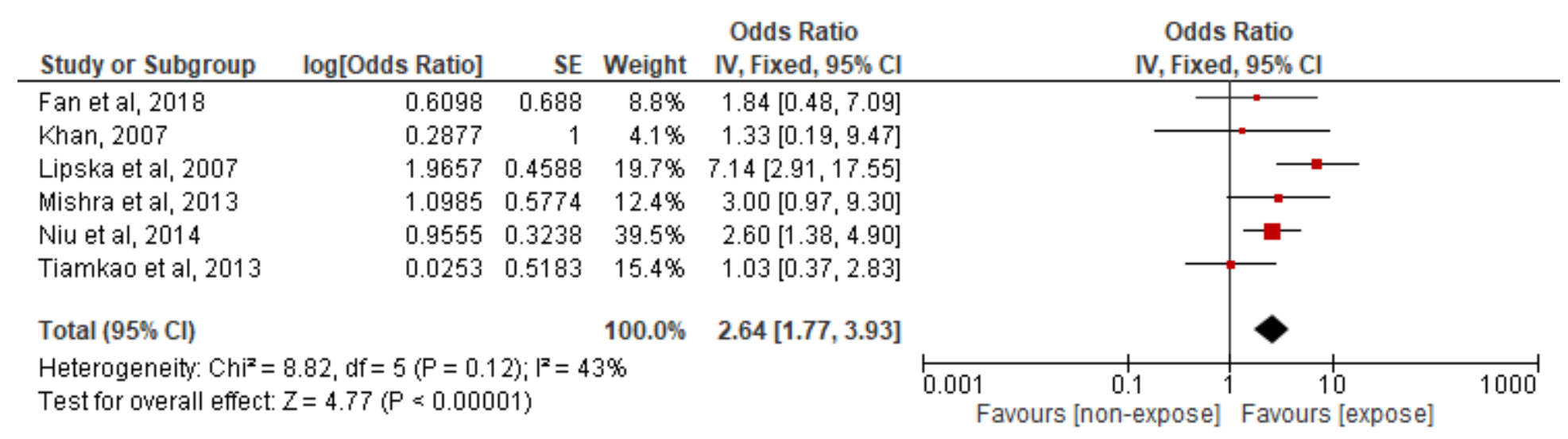

Figure 4. Meta-analysis of smoking and stroke risk at a young age 


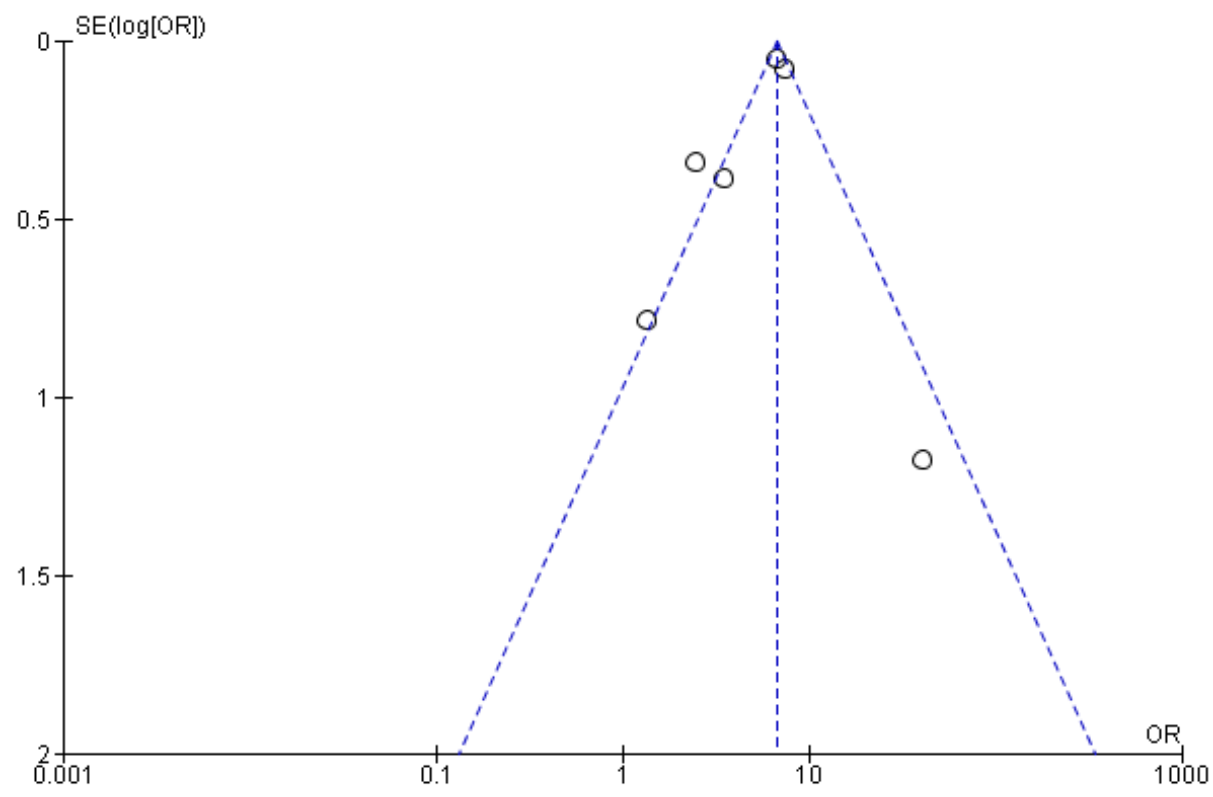

Figure 5. Funnel plots of hypertension and risk of stroke at a young age

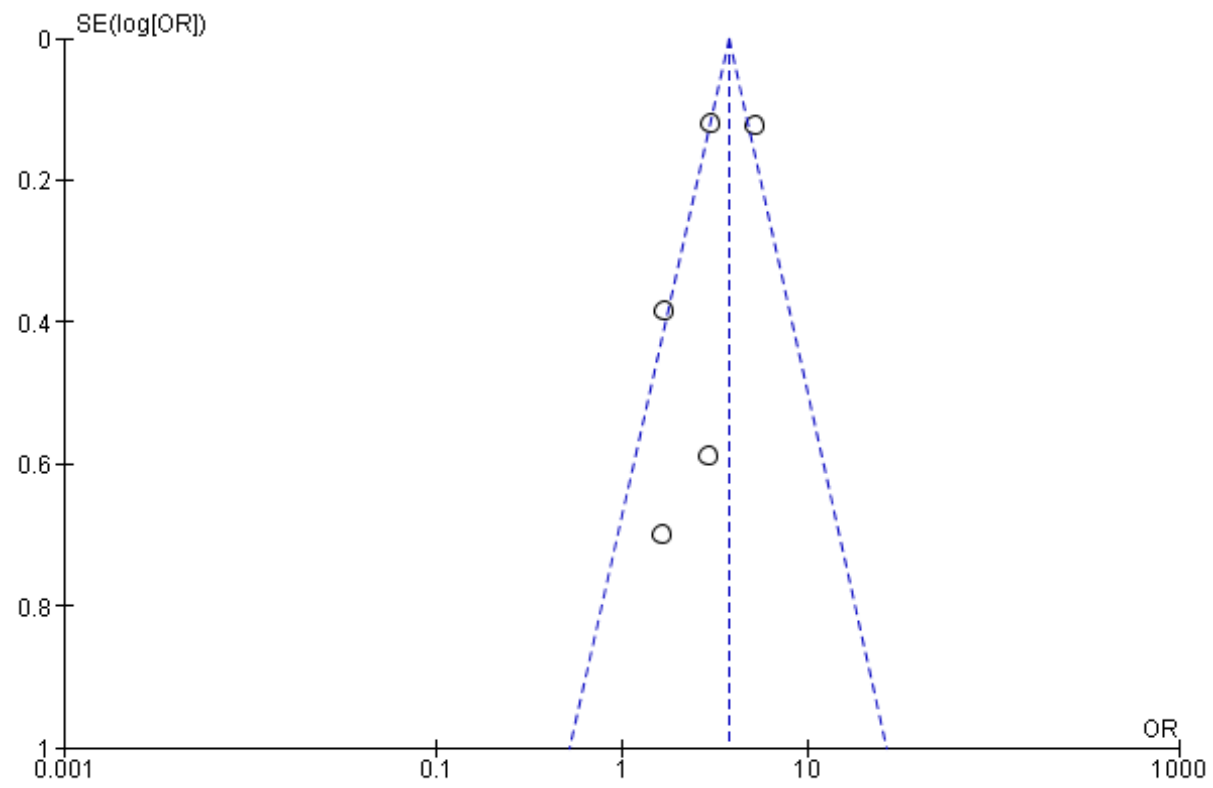

Figure 6. Funnel plot of type II DM and risk of stroke at a young age

Figure 4 shows that five articles reports that smoking is a risk factor for stroke at a young age. The results obtained showed a low heterogeneity between trials $(\mathrm{p}>0.001$; I $2=43 \%)$ so that the fixed effects model was used. Smoking can increase 2.6 times the risk of having a stroke at a young age (OR 2.64; CI 95\% 1.77 to 3.93). Figure 6 shows a symmetrical face facing down indicating that there was no publication bias in the study. 


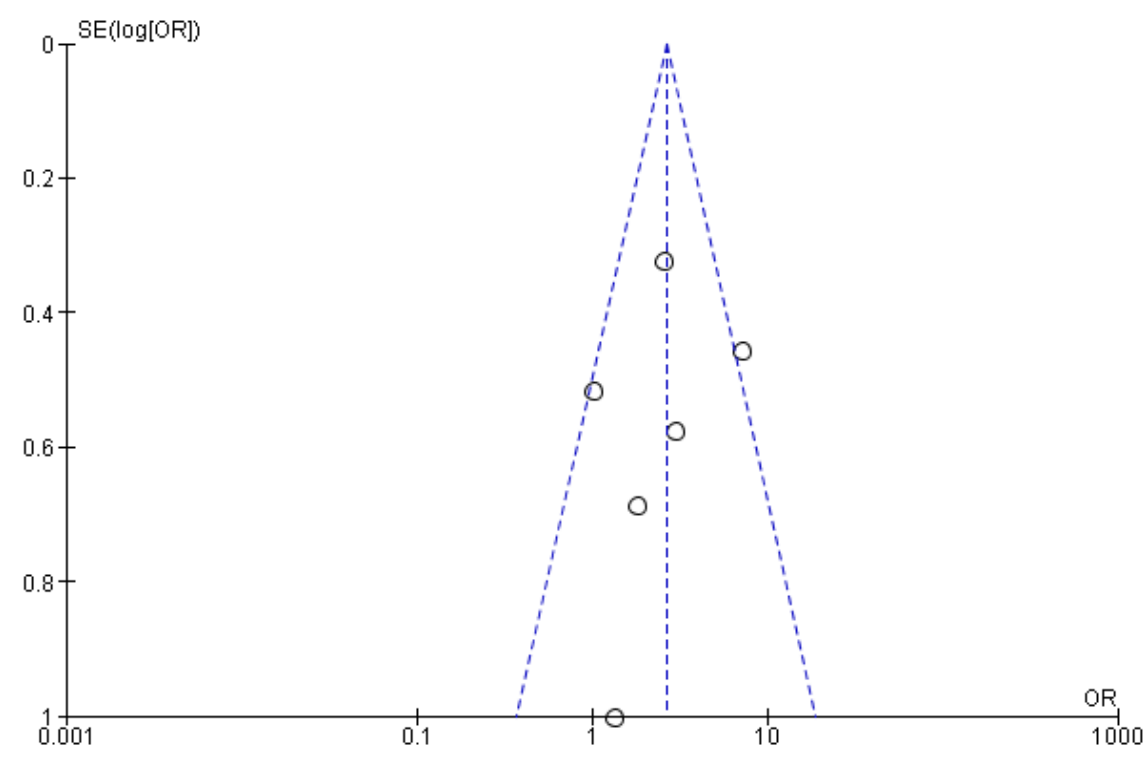

Figure 7. Funnel smoking and risk of stroke at a young age

\section{DISCUSSION}

Stroke at a young age was reported to have high mortality and cause an increase in DALY. The prevalence of stroke at a young age varies in each country, while its incidence continues to experience enhancement.

The incidence of stroke at a young age increases with increasing age of patients over 35 years, higher in women than men aged $18-44$ years, and increasing by $23 \%$ in a decade (Ekker et al., 2019). The negative impacts caused cause the importance of known risk factors.

Risk factors for stroke at a young age are divided into biological factors and factors related to lifestyle. Some conditions also pose risks such as premature pregnancy. Various types of risk factors have been studied in the last decade. This metaanalysis contains 26,360 samples. The results of the study reinforce previous studies that smoking history, type II diabetes, and smoking are significant risk factors that influence the occurrence of stroke at a young age.

\section{Hypertension}

The results of the meta-analysis of six articles on hypertension and the incidence of stroke at a young age showed that hypertension was a risk factor and could increase the risk 6.6 times compared to those without hypertension (OR 6.66; 95\% CI 6.10 to 7.27). These results are supported by Aigner et al. (2017) who reported hypertension to be an independent risk factor for stroke at a young age. Similarly, in the Clinical Hypertension and Vascular Disease (2016) book, it is explained that uncontrolled hypertension is a major factor in stroke in both young adults and elderly people.

The finding of hypertension is at a high young age. The Baltimore-Washington Cooperative Young Stroke study, a population-based case control study (patients aged 18-44 years), showed a positive relationship between hypertension and the risk of ischemic stroke in white and black people, both men and women (Putaala, 2016). 


\section{Diabetes Melitus type II}

The results of the meta-analysis of five articles on type II DM and stroke at a young age showed that type II DM was a risk factor and could increase risk 3.7 times compared to those without type II DM (OR 3.72; 95\% CI 3.17 to 4.38 ).

High levels of blood sugar in the body pathologically play a role in increasing the concentration of glycoprotein, which is the originator of vascular disease. High blood glucose levels will increase the likelihood of expanding the infarct area due to the formation of lactic acid which is an anaerobic glucose metabolism (Putaala, 2016).

\section{Smoking}

The results of a meta-analysis of five articles about smoking and stroke at a young age showed that smoking was a risk factor and could increase the risk 2.6 times compared to non-smokers (OR 2.64; CI 95\% 1.77 to 3.93 ). This is in accordance with the study conducted by Shah \& Cole (2010), namely the higher the frequency of smoking would increase the risk of stroke.

\section{AUTHOR CONTRIBUTIONS}

Windhy Monica is the main author who played a role in collecting and processing research data. Vitri Widyaningsih and Endang Sutisna Sulaeman examined the conceptual framework and research methodology.

\section{CONFLICT OF INTEREST}

We declare that there is no conflict of interest.

\section{FUNDING AND SPONSORSHIP}

This study does not require costs due to secondary data and the use of accessible databases and provides open access journals.

\section{ACKNOWLEDGEMENT}

We would like to thank database (Pubmed, ClinicalKey, and Google Scholar) for providing information and data in published journals.

\section{REFERENCE}

Aigner A, Grittner U, Rolfs A, Norrving B, Siegerink B, Busch MA (2017). Contribution of Established Stroke Risk Factors to the Burden of Stroke in Young Adults. Stroke, 48(7):17441751. doi: 10.1161/STROKEAHA.117.016599.

Andreadis (2016). Hypertension and Cardiovascular Disease. Springer: Switzerland.

Research and Development Agency of the Ministry of Health of the Republic of Indonesia (2018). Riset Kesehatan Dasar 2018 (2018 Basic Health Research). Balitbang Kemenkes RI. Retrieved from http://www.depkes.go.id/resources/download/info-terkini/hasil-riskesdas-2018.pdf

Ekker MS, Verhoeven JI, Vaartjes I, van Nieuwenhuizen KM, Klijn CJM, de Leeuw FE (2019). Stroke incidence in young adults according to age, subtype, sex, and time trends. Neurology, 92(21): e2444-e2454. doi: 10.1212/WNL.0000000000007533.

Feigin VL, Norrving B, Mensah GA (2017). Global Burden of Stroke. Circ Res., 120(3): 439-448.

Haidich $A B$ (2010). Meta-analysis in medical research. Hippokratia, 14(1): 29-37. Retrieved from https://www.ncbi.nlm.nih.gov/pmc/articles/PMC 3049418/

Liberati A, Altman DG, Tetzlaff J, Mulrow C, Gøtzsche PC, Ioannidis JP, Clarke $\mathrm{M}$, et al. (2009). The PRISMA statement for reporting systematic reviews 
Journal of Epidemiology and Public Health (2019), 4(4): 296-306

https://doi.org/10.26911/jepublichealth.2019.04.04.04

and meta-analyses of studies that evaluate health care interventions: explanation and elaboration. PLoS Med., 6(7): e1000100. https://doi.org/10.1136/bmj.b270o

Maaijwee NA, Rutten-Jacobs LC, Schaapsmeerders P, van Dijk EJ, de Leeuw FE (2014). Ischaemic stroke in young adults: risk factors and long-term consequences. Nat Rev Neurol. 10(6): 315-325. doi: 10.1038/nrneurol.2014.72 .

Murti B (2018). Prinsip dan Metode Riset Epidemiologi (Epidemiology Principles and Research Methods). Edisi IV. Cetakan I. Program Studi Ilmu Kesehatan Masyarakat, Program Pascasarjana, Universitas Sebelas Maret, Surakarta.

Putaala $J$ (2016). Ischemic stroke in the young: Current perspectives on incidence, risk factors, and cardiovascular prognosis. Eur Stroke J. 1(1): 28-40. doi: $10.1177 / 2396987316629860$.

Shah RS, Cole JW (2010). Smoking and stroke: the more you smoke the more you stroke. Expert Rev Cardiovasc Ther. 8(7): 917-32. doi: 10.1586/erc.10.56 .

Singhal AB, Biller J, Elkind MS, Fullerton HJ, Jauch EC, Kittner SJ, Levine DA, et al. (2013). Recognition and mana- gement of stroke in young adults and adolescents. Neurology, 81(12): 10891097. doi: 10.1212/WNL.obo13e3182a4a 451

Smajlović D (2015). Strokes in young adults: epidemiology and prevention. Vasc Health Risk Manag., 11: 157-164. doi: 10.2147/VHRM.S53203

Sousa MR, Ribeiro AL (2009). Systematic review and meta-analysis of diagnostic and prognostic studies: a tutorial. Arq Bras Cardiol. 92(3): 229-38, 23545. Retrieved from http://www.scielo.br/pdf/abc/v92n3/en_13.pdf

World Health Organization (2013). A global brief on hypertension: silent killer, global public health crisis: World Health Day 2013. World Health Organization. Retrieved from http://www.who.int/iris/handle/10665/79059

World Health Organization (2018). Global Health Estimate 2016: Death by Age, Sex, by Country and Region, 20002016. Geneva: World Health Organization. Retrieved from http://who.int/iris/bitstream/handle/10665/272596 